\title{
A formaçáo de valores e a prática da atençáo primária na saúde com estudantes de odontologia
}

\author{
Heriberto Fiuza Sanchez ${ }^{1}$, Carlos José de Paula Silva ${ }^{1}$, Marisa Maia Drumond ${ }^{2}$, Efigênia Ferreira e Ferreira ${ }^{3}$
}

Resumo: As ações que o sistema público de saúde brasileiro, chamado Sistema Único de Saúde (SUS) propõe passam pela valorização da Atenção Primária na Saúde (APS). Para isso os recursos humanos envolvidos precisam estar preparados. O objetivo desse trabalho foi avaliar concepçóes de dimensóes relacionadas à APS junto a alunos do $8^{\circ}$ e $9^{\circ}$ períodos de uma faculdade de odontologia de uma universidade pública no Brasil, com participaçáo do universo dos alunos. Questionários individuais abordando as dimensões foram aplicados por um único pesquisador. As respostas foram analisadas pelo programa BioStat 4.0. Os pesquisados entendem "visão do processo saúde-doença " de maneira ampliada e que "tecnologias apropriadas" são limitadas às chamadas tecnologias duras e leve-duras com muito pouca menção ao uso de tecnologias leves. Para "humanização do atendimento" definem que ética representa um compromisso com a dignidade da vida humana e solidariedade deve ser entendida de maneira politizada; vínculo é estabelecido além de competências técnicas profissionais e responsabilização reflete a priorizaçáo da pessoa. Por outro lado não compreendem que ética e solidariedade são tecnologias passíveis de estudo aprofundado sendo entendidas pelos alunos como "valores" que não podem ser sistematizados em conteúdos curriculares.

Palavras-chave: ensino odontológico, bioética, odontologia, atenção primária

\section{La formación de valores y la práctica de atención primaria en salud con estudiantes de odontología}

Resumen: Las acciones que propone el sistema brasilero de salud pública, llamado Sistema Único de Salud (SUS), dependen de la valorización de de la Atención Primaria en Salud (APS). Por ello, los recursos humanos involucrados deben estar preparados. El objetivo de este trabajo fue evaluar conceptos de dimensiones relacionadas con APS entre estudiantes de octavo y noveno periodos de una facultad de odontología en una universidad pública de Brasil, con la particpación de un universo de alumnos. Para abordar las dimensiones, un solo investigador aplicó cuestionarios individuales. Las respuestas fueron analizadas con el programa BioStat 4.0. Los encuestados entienden "el proceso salud-enfermedad" de manera amplia y que las "tecnologías adecuadas" están limitadas a las llamadas tecnologías duras y medianamente duras, con muy poca mención del uso de tecnologías livianas. Respecto de la "humanización de la atención", piensan que la ética representa un compromiso con la dignidad humana y que la solidaridad debe entenderse de manera política; además, establecen un vínculo entre experiencia técnica y responsabilidad, reflejada en la priorización de la persona. Por otro lado, no comprenden que es posible un estudio profundo de la ética y la solidaridad, entendiéndolas en cambio como "valores" que no pueden ser sistematizados en el contenido curricular.

Palabras clave: educación dental, bioética, atención primaria, odontología

\section{Training in values and the practice of primary health care with oral health students}

Abstract: The interventions that public health Brazilian system propose, denominated Unique Health System (UHS) depend on the value given to Primary Health Care (PHC). Therefore, human resources involved must be prepared. The aim of this study was to evaluate dimension concepts related to PHC by students of eight and nine periods of Dentistry Department of a Brazilian Public University, with the participation of a sample of students. In order to study the dimensions, one researcher applied individual questionnaires. The answers were analyzed with BioStat 4.0 program. Respondents understand broadly "the process health-disease" and that "adequate technologies" are limited to hard and medium technologies, with little mention to the use of soft technologies. With respect to "humanizing health care", they belief that ethics represent a compromise with human dignity and that solidarity must be understood politically; furthermore, they establish a link between technical experience and responsibility, reflected in giving priority to the person. On the other hand, they do not understand that it is possible a deep study of ethics and solidarity, understanding them more as "values" which cannot be systematized in curricular content.

Key words: dentistry education, bioethics, primary health care, oral health

\footnotetext{
${ }^{1}$ Mestre em Odontologia em Saúde Coletiva. Departamento de Odontologia Social e Preventiva, Faculdade de Odontologia da Universidade Federal de Minas Gerais, Belo Horizonte MG, Brasil

Correspondência: heribertofsanchez@yahoo.com.br

${ }^{2}$ Doutora em Odontologia Social e Preventiva. Professora Adjunta, Departamento de Odontologia Social e Preventiva, Faculdade de Odontologia da Universidade Federal de Minas Gerais, Belo Horizonte MG, Brasil

${ }^{3}$ Doutora em Epidemiologia. Professora Adjunta, Departamento de Odontologia Social e Preventiva, Faculdade de Odontologia da Universidade Federal de Minas Gerais, Belo Horizonte MG, Brasil
} 


\section{Introdução}

A necessidade de adequada atuação dos recursos humanos envolvidos na produção da saúde das comunidades é fato repetidamente lembrado e debatido em vários momentos da trajetória histórica do sistema público brasileiro, o Sistema Único de Saúde (SUS) (1).

O Ministério da Saúde brasileiro definiu que o eixo estruturante do SUS passa pela valorização da atenção primária na saúde (APS), através de diferentes programas ou estratégias, sendo a principal delas a Estratégia Saúde da Família(2), que incluiu entre suas ações a odontologia, em 2000(3).

A APS é considerada um nível da atenção à saúde dirigida por valores de dignidade humana, equidade, solidariedade e ética(4). A atuação dos cirurgióes dentistas náo deve se limitar a um "adestramento" teórico-prático, devendo os profissionais ter amplos conhecimentos científicos relacionados aos valores das pessoas, cuidando da vida como um valor primário e respeitando a dignidade e integridade dos usuários, atuando com solidariedade, em busca de excelência e equidade(5). Existe ainda a necessidade de que o profissional de saúde tenha uma postura ética na relação com o paciente, com outros profissionais e com a sociedade em geral respeitando os interesses do indivíduo e da coletividade(6).

Todas as formas de tecnologia são necessárias para o enfrentamento dos problemas de saúde, mas no processo de trabalho da APS ganha importância o uso das chamadas tecnologias leves (7), entendidas como aquelas que possibilitam produzir acolhimento, vínculo, responsabilização e autonomia(8).

Os profissionais de saúde na APS devem cultivar uma relação de confiança com a população, conquistada a partir da capacidade de diálogo (o que implica saber escutar) e em aceitar o outro e seus saberes, o que se reflete em humanização $(9,10)$. A humanização é caracterizada pelo vínculo e o resultado natural deste é a responsabilização, ou seja, a implicação com os problemas e demandas dos usuários, garantindo respostas resolutivas, tornando-o corresponsável pelo enfrentamento dos fatores associados com o processo saúdedoença (11).

O reconhecimento de que o processo saúdedoença das comunidades não possui uma etiologia única, biológica, sendo fruto de uma complexa teia de fatores, relacionados particularmente às condiçóes de vida e existência dos indivíduos é outra característica desejável daqueles que desejam atuar na APS(12). Esse entendimento ampliado conduz a prática do profissional de saúde na APS para a atenção à pessoa e não à sua enfermidade, verdadeira valorização e priorização da responsabilidade por alguém(13).

É reconhecida a necessidade da adequada formaçáo do cirurgião dentista para a APS, por se reconhecer a importância desse nível de atenção em um sistema de saúde organizado em níveis $(14,15)$. No entanto, no campo da formaçáo do profissional de saúde ainda se verifica a formação dissociada da realidade, com ênfase na especialização e práticas desintegradas de atenção(16). Além disso, as Instituições de Ensino Superior possuem dificuldades em superar os entraves epistemológicos e mercadológicos, profundamente enraizados em seus interiores(17). Ou seja, profissionais continuam sendo formados em um modelo que não responde às necessidades e desafios que são colocados pelo SUS.

Profissionais de saúde que não conseguem romper com o modelo de formação hegemônico, considerado inadequado para a APS, tendem a apresentar uma prática clínica medicalizante e de altos custos, que gera baixa autonomia para os usuários, sendo incapaz de atuar em determinantes de saúde coletivos(18). Dessa forma, a dificuldade da Estratégia Saúde da Família em contribuir para a ruptura do modelo hegemônico parece estar associada à escassez de recursos humanos capacitados e/ou com perfil adequado(19).

A pergunta que motiva a execução deste trabalho é relacionada à capacidade de atuação do cirurgiāo dentista na APS. Deste modo, o propósito do presente estudo foi avaliar a formação de va- 
lores fundamentais para a prática humanizada na Atenção Primária na Saúde, junto a acadêmicos de um curso de graduação em odontologia.

\section{Metodologia}

Participaram deste estudo alunos do $8^{\circ}$ e $9^{\circ}$ períodos do curso de graduação em odontologia e a coleta dos dados se deu no final do período letivo, $1^{\circ}$ semestre de 2008 . A escolha por acadêmicos desses períodos foi proposital, uma vez que correspondem aos alunos que já receberam, ao longo do curso de odontologia, embasamento teórico e prático, incluindo o tema específico APS e são considerados capacitados para o enfrentamento da prática profissional. A diferença entre os acadêmicos do $8^{\circ}$ e $9^{\circ}$ períodos é que, os primeiros ainda não realizaram as atividades do Internato Rural, disciplina que se desenvolve em pequenos municípios e que permite contato com situaçóes reais de APS. Todos os acadêmicos do $8^{\circ}$ período ( 43 alunos) e $9^{\circ}$ período (63 alunos) participaram do estudo.

A coleta de dados se deu a partir da aplicação de um questionário estruturado contendo perguntas que contemplavam três dimensóes. Procurou-se elaborar perguntas que refletissem diferentes visóes acerca das citadas dimensões. $\mathrm{Na}$ escolha das dimensóes que geraram as perguntas procurou-se verificar junto aos acadêmicos entrevistados, as suas concepçóes sobre dimensões essenciais à APS: a visão ampliada do processo saúde-doença contemplando a pessoa e não somente a enfermidade; a tecnologia necessária para o trabalho na APS, entendida como um nível de atenção à saúde que utiliza tecnologias de elevada complexidade e baixa densidade; a humanização no atendimento, entendida como vínculo e responsabilização, ética e solidariedade $(4,12,20,21)$.

A segunda etapa do questionário objetivava conhecer as possibilidades de aprendizado de alguns valores universais: "ética", "solidariedade", "estabelecimento de vínculo" e "responsabilidade no cuidar" na APS. Os acadêmicos deveriam enumerar em ordem crescente de importância na formação as instituições (escola de segundo grau, amigos, família, faculdade de odontologia e religião) que mais contribuíram na aquisição destes valores.

Previamente à realização da pesquisa foram realizados dois testes piloto, com 6 alunos do $7^{\circ}$ período da mesma instituição, para adequação do instrumento.

O preenchimento foi realizado sem nenhum tipo de esclarecimento por parte do pesquisador e para cada pergunta deveria ser marcada uma opçáo de resposta. Foram entregues aos sujeitos da pesquisa e recolhidos assim que eram preenchidos, em momento de aula teórica.

Para a análise dos dados obtidos as opçóes de cada dimensão foram graduadas, com pesos de 1 a 3 (todas as dimensões apresentavam três opçóes), e cada aluno teve uma pontuaçáo final (de 0 a 9 pontos). A pontuaçáo total do $8^{\circ}$ período poderia variar de 0 a 129 pontos e a do $9^{\circ}$, de 0 a 189 pontos. A análise estatística foi realizada no programa BioEstat versão 4.0, utilizando-se freqüências absoluta e relativa, média e desvio padrão e moda. Para a relação das respostas entre os dois períodos do curso $\left(8^{\circ}\right.$ e $\left.9^{\circ}\right)$, utilizou-se o teste Mann Whitney (nível de confiança de 0,95).

A presente pesquisa foi aprovada pelo Comitê de Ética em Pesquisa (COEP) da UFMG através do Parecer $n^{\circ}$. ETIC 248/08.

\section{Resultados}

Os resultados da descrição e análise das dimensóes estão expostos na tabela 1.

A tabela 2 apresenta os resultados com relaçáo às instituiçóes responsáveis na formação de valores dos acadêmicos.

\section{Discussão}

A partir da análise da tabela 1 , verifica-se inicialmente que entre os dois períodos estudados não se observou diferença estatisticamente significante. 
A formação de valores e a prática da atenção primária na saúde com estudantes de odontologia - Heriberto Fiuza Sanchez et al.

\begin{tabular}{|c|c|c|c|c|c|c|c|}
\hline \multirow{2}{*}{ Dimensão } & \multicolumn{3}{|c|}{$8^{\circ}$ período } & \multicolumn{3}{|c|}{$9^{\circ}$ período } & \multirow[b]{2}{*}{$\begin{array}{l}\text { Valor } \\
\text { de p }\end{array}$} \\
\hline & $\begin{array}{l}\text { Total de } \\
\text { pontos }\end{array}$ & média(dp) & Mo & $\begin{array}{l}\text { Total de } \\
\text { pontos }\end{array}$ & média(dp) & Mo & \\
\hline $\begin{array}{l}\text { Visão do } \\
\text { processo saúde } \\
\text { doença }\end{array}$ & $\begin{array}{l}116 \\
(89,9 \%)\end{array}$ & $2,70 \pm 0,56$ & 3 & $\begin{array}{l}180 \\
(95,2 \%)\end{array}$ & $2,86(0,47)$ & 3 & 0,254 \\
\hline $\begin{array}{l}\text { Tecnologias } \\
\text { apropriadas }\end{array}$ & $\begin{array}{l}61 \\
(47,3 \%) \\
\end{array}$ & $1,42 \pm 0,54$ & 1 & $\begin{array}{l}102 \\
(53,9 \%)\end{array}$ & $1,62 \pm 0,68$ & 2 & 0,187 \\
\hline $\begin{array}{l}\text { Humanizaçáo } \\
\text { do atendimento }\end{array}$ & $\begin{array}{l}98 \\
(75,9 \%)\end{array}$ & $2,29 \pm 0,77$ & 3 & $\begin{array}{l}152 \\
(80,4 \%)\end{array}$ & $2,42 \pm 0,69$ & 3 & 0,100 \\
\hline
\end{tabular}

Tabela 1: Total da pontuação obtida, média e moda, por período, e valor de p resultante da comparação entre os grupos, 2008

\begin{tabular}{|c|c|c|c|c|}
\hline \multirow[t]{2}{*}{ Valores } & \multicolumn{2}{|l|}{$8^{\circ}$ período } & \multicolumn{2}{|l|}{$9^{\circ}$ período } \\
\hline & $1^{\text {a }}$ opção & $2^{\text {a }}$ opção & 1a opção & $2^{\text {a opção }}$ \\
\hline $\begin{array}{l}\text { Ser ético nas relações com pessoas, } \\
\text { pacientes, comunidade }\end{array}$ & $\begin{array}{l}\text { Família } \\
65,1 \%\end{array}$ & $\begin{array}{l}\text { Faculdade } \\
27,9 \%\end{array}$ & $\begin{array}{l}\text { Família } \\
82,5 \%\end{array}$ & $\begin{array}{l}\text { Religião } \\
30,6 \%\end{array}$ \\
\hline $\begin{array}{l}\text { Ser solidário com pessoas, pacientes, } \\
\text { comunidades }\end{array}$ & $\begin{array}{l}\text { Família } \\
79,1 \%\end{array}$ & $\begin{array}{l}\text { Faculdade } \\
37,2 \%\end{array}$ & $\begin{array}{l}\text { Família } \\
83,9 \%\end{array}$ & $\begin{array}{l}\text { Faculdade } \\
39,3 \%\end{array}$ \\
\hline $\begin{array}{l}\text { Saber criar vínculo com aqueles que } \\
\text { proporciono açôes voltadas para a } \\
\text { saúde }\end{array}$ & $\begin{array}{l}\text { Faculdade } \\
69,8 \%\end{array}$ & $\begin{array}{l}\text { Amigos } \\
33,3 \%\end{array}$ & $\begin{array}{l}\text { Faculdade } \\
57,4 \%\end{array}$ & $\begin{array}{l}\text { Faculdade } \\
33,3 \%\end{array}$ \\
\hline $\begin{array}{l}\text { Responsabilizar-me pelas minhas açóes } \\
\text { de cuidado aos meus pacientes }\end{array}$ & $\begin{array}{l}\text { Faculdade } \\
67,4 \%\end{array}$ & $\begin{array}{l}\text { Família } \\
45,2 \%\end{array}$ & $\begin{array}{l}\text { Faculdade } \\
46,8 \%\end{array}$ & $\begin{array}{l}\text { Faculdade } \\
41,0 \%\end{array}$ \\
\hline
\end{tabular}

Tabela 2: Possibilidades de aprendizado de alguns valores universais, em percentuais, entre os grupos, 2008

$\mathrm{Na}$ primeira dimensão analisada, "visão do processo saúde-doença”, observou-se uma pontuação elevada nos dois períodos. É importante afirmar que esta pontuação reflete uma visão ampliada da determinaçáo social da saúde-doença entre os alunos, uma vez que a alternativa de resposta "manifestação de doenças pela interação do homem com suas condiçóes de trabalho, vida, moradia, existência" recebeu peso 3 e essa foi a alternativa mais marcada pelos períodos estudados.

A relação existente entre saúde e doença não é apenas uma relação do bom ou mau funcionamento do corpo, mas uma interação muito mais ampla do homem com os ambientes físicos e sociais que o cercam, da sua maneira de relacionar- se com outros homens, da sua condição de trabalho, da forma como é organizada a produção de riquezas e como essas riquezas são repartidas, das possibilidades que possui de se expressar, para desenvolver seu potencial criativo e se desenvolver como pessoa (22).

Essa visão ampliada é altamente desejável para aqueles que pretendem trabalhar em um programa de APS. Fator positivo a ser destacado também é o fato de que a monocausalidade, táo ligada ao imaginário das doenças bucais, sobretudo cárie e doença periodontal, e muitas vezes reforçada pelos profissionais em sua prática profissional diária, foi fato muito pouco lembrado, tendo sido assinalado por apenas 1 aluno do $8^{\circ}$ período. 
O reconhecimento da determinação social da saúde-doença pode se constituir em crédito para uma prática do cuidado, baseado na atenção à saúde (reconhecendo essa complexa teia e tentando intervir nos fatores desencadeantes dos processos patológicos), e não meramente na assistência(23), portanto em uma atuação profissional mais efetiva.

$\mathrm{Na}$ dimensão "tecnologias apropriadas", destacase que o $8^{\circ}$ período assinalou com maior frequência a alternativa que possuía peso 1, "aparelhos, instrumentos para exames, materiais de consumo que são utilizados nas açôes de intervenção diretas realizadas sobre os pacientes", enquanto o $9^{\circ}$ período assinalou na sua maioria a alternativa que possuía peso 2, "conhecimentos adquiridos e saberes profissionais aplicados de uma forma estruturada, organizada no contato com os pacientes".

Uma pontuação mais reduzida para a dimensão "tecnologias apropriadas" (tabela 1) demonstra que os alunos entendem "tecnologias apropriadas" como sendo o uso de tecnologias duras e leve-duras. A opção que representou o uso de tecnologias leves, "capacidade de dialogar, escutar e aceitar o outro em sua história de vida", valorada com peso 3 , foi a menos apontada $(2,32 \%$ e $3,17 \%$ das respostas, $8^{\circ}$ e $9^{\circ}$ períodos respectivamente).

A pouca opção pelos alunos de ambos os períodos por uma tecnologia relacionada à humanizaçáo e valorização do cuidado revelam que, em sua opiniáo o uso das chamadas tecnologias leves pode não se enquadrar bem no rol "tecnologias". Pediu-se para marcar a opção que se identificasse melhor com "tecnologia adequada" e a associação feita pelo $8^{\circ}$ período se relaciona fortemente a material, instrumental e equipamento. Este fato pode ser observado quando analisadas as repostas à terceira dimensão, humanização, com forte vínculo nas tecnologias leves. Não se pode afirmar que eles não dêem importância à tecnologia leve, mas esta modalidade, para eles, não é tecnologia.

Destaca-se que embora não explicitamente, o $9^{\circ}$ período aventou para a hipótese de "outros saberes" necessários para o "contato com os pacientes".

É possível que os alunos interpretem valores e atitudes relacionados à tecnologia leve, como a capacidade de relacionamento, humanização e ética, como sendo aspectos subjetivos do ser humano, não passíveis de uma teoria e aprendizado, sendo atributos que dependeriam de cada um e, portanto, não sendo encarados como uma forma de tecnologia, semelhante ao descrito por outros autores $(18,24)$. Esses descreveram a existência de dois tipos de medicina: a hospitalar, ligada à medicina "científica" e a não hospitalar, que envolveria saberes "não científicos", e estaria ligada à atividades de APS.

Todas as formas de tecnologia são necessárias na prática diária dos profissionais de saúde, ainda mais se considerarmos o desafio imposto pela integralidade. Embora as tecnologias não sejam excludentes entre si, é desejável o correto manejo das tecnologias leves em ambientes de APS para conformação de novas práticas nesse nível de atenção $(9,18)$. Os usuários de serviços de APS identificam a necessidade das diversas formas de tecnologia. Ao avaliar os serviços, apontam desde a falta de eventuais aparelhos ou a dificuldade de acesso aos mesmos até a falta que sentem quando não são cumprimentados ou não recebem atenção quando procuram serviços de saúde(7). Seria desejável que os alunos identificassem também esta diferença, como forma de busca de aprimoramento em todas as tecnologias.

A terceira dimensão analisada, "humanização no atendimento", mereceu pontuaçôes mais altas entre os dois períodos. Esta pontuação verificada, em ambos os períodos, pode apontar para posturas profissionais adequadas para o trabalho na APS. As alternativas mais marcadas pelos alunos pesquisados nas perguntas que analisavam essa dimensão foram aquelas que possuíam maior peso. Nessa dimensão foram analisadas a ética e a solidariedade, o vínculo e a responsabilização na APS.

Para a maioria dos pesquisados, ética na APS representa "a reflexáo sobre os atos humanos, o quanto são justos ou injustos, bons ou maus, corretos ou incorretos". Entendem que essa dimensão vai muito além das preocupações de ordem científica das pesquisas que envolvem algumas das chama- 
das "situaçôes limite" ou de "fronteiras da vida", como as relacionadas às células-tronco e engenharia genética(25). Conseguem definir que ética na APS representa um compromisso maior, com a dignidade da vida humana.

Tais valores éticos são altamente desejáveis na APS, especialmente se levarmos em consideração a pressão que o mercado exerce pela incorporação de novas tecnologias duras, com a utilizaçâo cada vez mais frequente de técnicas e materiais, não só pelos fabricantes e fornecedores, como também pelos pacientes e profissionais que buscam soluçóes para os mais diversos problemas odontológicos. Esta pressão do mercado pode influenciar diretamente no distanciamento dos profissionais dos valores éticos, equivocadamente, uma vez que esses avanços não deveriam ser contrários à aplicação de uma ética adequada que servisse aos pacientes e profissionais.

A solidariedade foi apontada pela maioria dos pesquisados como "comprometimento com a causa social, buscando autonomia e cidadania do paciente". Essa visão é mais politizada e se aproxima da chamada solidariedade crítica(26). Nesse caso, a solidariedade não se restringiria a uma relação assistencialista, ao contrário, possuiria um elemento político que tem como referência o Estado. A capacidade de entendimento dessa dimensão política, intimamente relacionada à cidadania e à capacidade de intervenção de políticas públicas também é parte dessa solidariedade crítica. A solidariedade crítica exige dos sujeitos envolvidos, no caso dos profissionais da APS, engajamento, politização e comprometimento com a causa social.

Um dos sintomas mais marcantes da crise civilizacional que vivemos, caracterizada por promover distanciamento e solidáo entre as pessoas, algo tão contraditório por partir da mesma sociedade que criou vários mecanismos de conhecimento e comunicação, é a perda da essência humana, representada pelo cuidado. Caminhos de cura passam necessariamente pelo resgate do cuidado, entendido como a possibilidade de valorização da solidariedade, valor humano abalado pela hegemonia do neoliberalismo, que suporta o individualismo e exalta a propriedade privada, valorizando a es- tética em detrimento da ética. Passam ainda pela apreciação de valores éticos capazes de transformar a ciência e a tecnologia em medicinas para a humanidade e não para a satisfação e enriquecimento de poucos(27).

Vale ser ressaltado, contudo, que em uma unidade de APS é desejável que os profissionais envolvidos saibam cultivar diversas formas de solidariedade. A produção do cuidado envolve diretamente a abordagem respeitosa e humana, se aproximando assim das definiçôes apresentadas para a ética. No contexto e momento apropriado, devem ser trabalhadas importantes discussões emancipatórias dos indivíduos, estimulando a cidadania plena, caracterizando assim a chamada solidariedade crítica. A atuação profissional deve se balizar pelo equilíbrio entre as diversas formas de solidariedade anteriormente apresentadas.

Sem o resgate da dimensão cuidadora, representada por valores éticos e de solidariedade, deixamos de ser seres humanos. Mergulhamos em um mundo de competição e alienação e ao desligarmos desses valores possivelmente perdemos muito do direito de sermos chamados de profissionais da saúde.

Para os pesquisados, vínculo na APS representa "ligaçáo com envolvimento, responsabilidade e participação, tanto do profissional quanto do paciente". Isso indica que os pesquisados entendem o vínculo nesse nível de atenção não somente como a ligaçáo entre as partes envolvidas (profissional e usuário) a partir de competências técnicas. Significa para eles que estabelecer vínculo requer envolvimento humano: os usuários precisam se envolver nos destinos que sua saúde pode tomar, conquistando sua autonomia e colocando-a em prática, com participação do profissional nessa conquista.

A responsabilização foi apontada como um valor que está acima da responsabilidade profissional, relacionada a procedimentos executados nos pacientes. Esteve ligada ao "compromisso profissional junto aos pacientes" ou "valorização e priorização da pessoa; zelo e dedicação profissional por alguém". Os pesquisados identificam a responsabilização, 
por um lado como sendo intimamente relacionada ao profissionalismo dos recursos humanos na área, como a capacidade de ser assíduo, pontual, tecnicamente competente, responsável pela população que assiste. Mas esse profissionalismo seria caracterizado por ter uma visão reduzida do processo saúde doença, o que não lhe permite entender a complexidade dos problemas sanitários que envolvem a população pela qual é responsável.

Por outro lado definem a responsabilização dentro de um referencial mais aproximado ao ideal para o trabalho na APS, ligado à priorização do ser humano. Tal postura por parte dos alunos pode ser um reflexo da própria formaçáo acadêmica na odontologia, que prioriza a técnica e pouco enfatiza a abordagem social dos problemas de saúde e pouco compreende a historicidade do ser humano, corroborando outro estudo realizado que apontou ainda que a qualificação do cirurgião-dentista para o SUS apresenta deficiências no campo da humanização do atendimento(28).

Quanto à pergunta final (tabela 2) verificou-se o peso que valores familiares possuem na determinação aquisição dos valores ética e solidariedade pelos alunos, o que contradiz pesquisa anteriormente feita(29). Mas, com relaçáo à análise relativa ao vínculo e responsabilidade na APS, os resultados apontam a faculdade como principal instituição responsável $(29,30)$.

Os resultados obtidos nessa última pergunta da pesquisa parecem mais uma vez indicar que os alunos pesquisados não compreendem que os valores ética e solidariedade são valores passíveis de estudo aprofundado a ser utilizado no cuidado dos pacientes e comunidades. Entendem que são adquiridas principalmente através de vias familiares e são interpretados pelos alunos como valores que não podem ser sistematizados em conteúdos curriculares. Tal fato não se justifica uma vez que são as universidades os locais aonde se adquirem e se modificam padróes ou modelos de conduta que serão aplicados na vida profissional(30). Por outro lado, parecem compreender que vínculo e responsabilização são aprendidos pelas vias pedagógicas da faculdade. Essa dicotomia estabelecida entre o aprendido da família ou da faculdade de odontologia pode ser uma incoerência uma vez que todas essas dimensões refletem um sentido maior de valorização e dignificação do ser humano.

\section{Conclusóes}

Os alunos pesquisados apresentam algumas posturas adequadas para o trabalho em APS. Por outro lado, demonstram que o modelo biomédico de ensino possui força significativa na sua formaçáo profissional e isso pode ser um grande obstáculo para a conformação de novas práticas. Para um maior conhecimento da questáo apresentada no presente trabalho, novas pesquisas que utilizem diferentes metodologias se fazem necessárias. $\mathrm{O}$ uso de uma metodologia qualitativa poderia ser adequada para um maior aprofundamento do objeto em estudo.

Observou-se que os pesquisados apresentaram visão ampliada do processo saúde-doença. Essa visão ampliada é altamente desejável para aqueles que pretendem trabalhar em um programa de APS. Observou-se também que os pesquisados apontaram para posturas profissionais adequadas para o trabalho na APS em relação à dimensão "humanização", que buscou analisar a ética e a solidariedade, o vínculo e a responsabilização nesse nível de atenção.

Por outro lado, para os pesquisados ser ético e solidário é algo aprendido principalmente pelas vias familiares, com a participaçáo secundária da formação superior nesse aprendizado. Acreditam, contudo, que estabelecer vínculo e responsabilizar-se no cuidado pelo outro são aprendidos pelas vias pedagógicas da universidade.

Ainda de acordo com os resultados obtidos no presente trabalho, observou-se que os pesquisados apresentaram padrão semelhante de respostas para o valor humano da ética, refletindo sobre os atos humanos e suas consequências. Esse dado também é considerado adequado para a atividade na APS. Pode representar para a saúde bucal a superação de um desafio: a necessidade de romper o "universo da boca" e a necessidade de considerar sua prática pautada em respeito ao outro, tolerân- 
cia e humildade. Saber trilhar esse caminho faz com que o trabalho na APS se afaste de referenciais biomédicos e se aproxime da incorporação da bioética nesse nível de atenção.

Por outro lado a crença que valores essenciais não podem ser desenvolvidos a partir de estudo sistematizado pode representar um desafio sobre o qual devem se debruçar as instituiçóes de ensino superior, não se limitando a uma disciplina, devendo ser objeto de esforço de todos para que se possa construir uma sociedade mais justa e humana.

\section{Referências}

1. Ceccim RB, Armani TB, Rocha CF. O que dizem a legislação e o controle social em saúde sobre a formação de recursos humanos e o papel dos gestores públicos, no Brasil. Ciência e Saúde Coletiva 2002; 7(2): 373-383.

2. Brasil. Ministério da Saúde. Secretaria de Assistência à Saúde. Coordenação de Saúde da Comunidade. Saúde da Família: uma estratégia para a reorientação do modelo assistencial. Brasília: Ministério da Saúde; 1997.

3. Brasil. Ministério da Saúde. Portaria No 1.444 de 28 de dezembro de 2000. Estabelece incentivo financeiro para a reorganização da atenção à saúde bucal prestada nos municípios por meio do Programa Saúde da Família. Brasília: 2000.

4. Starfield B. Atenção primária: equilibrio entre necessidades de saúde, serviços e tecnologia. Brasil: Ministério da Saúde, UNESCO; 2004.

5. Deangelillo CA. Importancia de las humanidades en odontoestomatología. Acta Bioethica 2006; 12(01): 55-58.

6. Musse JO, Boing AF, Martino FS, et al. O Ensino da bioética nos cursos de graduação em odontologia do estado de São Paulo. Arquivo de Ciências da Saúde 2007; 14(1): 13-16.

7. Ferri SMN, Pereira MJB, Mishima SM. As tecnologias leves como geradoras de satisfação em usuários de uma unidade de saúde da família. Interface-Comunicação, Saúde, Educação 2007; 11(23): 515-529.

8. Merhy EE. Saúde: a cartografia do trabalho vivo. São Paulo: Hucitec; 2002.

9. Schraiber LB, Nemes MIB, Mendes-Gonçalves RB, (orgs.) Saúde do adulto. Programas e açôes na unidade básica. 2a ed. São Paulo: Editora Hucitec; 2000.

10. Teixeira MCB. A dimensão cuidadora do trabalho de equipe em saúde e sua contribuição para a odontologia. Ciência e Saúde Coletiva 2006; 11(1): 45-51.

11. Brasil. Ministério da Saúde. Secretaria Executiva. Núcleo Técnico da Política Nacional de Humanização. HumanizaSUS: politica nacional de humanização: documento base para gestores e trabalhadores do SUS. Brasília; 2004.

12. Tavares MJ, Vianna R, Tura LFR. O cirurgião-dentista inserido no contexto social como promotor de saúde bucal. UFES Revista de Odontologia 2001; 3(1): 16-22.

13. Puccini T, Cecílio LCO. A humanização dos serviços e o direito à saúde. Cadernos de Saúde Pública 2004; 20(5): 1342-1353.

14. Atchison K, Mito R, Lefever K, McCauley K. Introduction to section: dentistry and primary care. An evaluation of postgraduate general dentistry training. Journal of Dental Education 2002; 66(6): 728-729.

15. Waterhouse P, Maguire A, Tabari D, Hind V, Lloyd J. The development of a primary dental care outreach course. European Journal of Dental Education 2008; 12(8): 8-16.

16. Gontijo LPT. Construindo as competências do cirurgião-dentista na atenção primária em saúde. Tese (Doutorado em Saúde Pública), Escola de Enfermagem de Ribeirão Preto, Universidade de São Paulo, Ribeirão Preto 2007.

17. Moysés SJ. Integralidade e ação prática: desafios para a força de trabalho em saúde Bucal no 
Brasil. In: Garcia DVG. Novos rumos da saúde bucal: os caminhos da integralidade. Rio de Janeiro: ABORJ/ANS/UNESCO; 2005.

18. Cunha GT. A construção da clínica ampliada na atenção básica. São Paulo: Hucitec; 2005.

19. Scherer MDA, Marino SRA, Ramos FRS. Rupturas e resoluções no modelo de atenção à saúde: reflexóes sobre a estratégia saúde da família com base nas categorias kuhnianas. Interface- Comunicação, Saúde, Educação 2005; 9(16): 53-66.

20. Brasil. Ministério da Educação. Resolução CNE/CES 3, de19 de fevereiro de 2002. Institui as Diretrizes Curriculares Nacionais nos Cursos de Odontologia. Diário Oficial, Brasília, 04 mar 2002, seção1, p. 10.

21. Brasil. Ministério da Saúde. Secretaria de Atenção à Saúde. Departamento de Atenção Básica. Saúde Bucal. Cadernos de atenção básica 2006; 17.

22. Marques CMS. Processo Saúde-doença. In: Guia Curricular para Formação do Atendente de Consultório Dentário para Atuar na Rede Básica do SUS: Áreas I e II. Brasília: Ministério da Saúde; 1998.

23. Narvai PC. Integralidade na atençâo básica à saúde. Integralidade? Atenção? Básica? In: Garcia DVG. Novos rumos da saúde bucal: os caminhos da integralidade. Rio de Janeiro: ABORJ/ANS/ UNESCO; 2005.

24. Almeida ELV. Medicina hospitalar - medicina extra-hospitalar: duas medicinas? Mestrado em Saúde Coletiva. Rio de Janeiro: IMS/UERJ; 1988.

25. Berlinguer G. Ética da saúde. São Paulo-SP: Hucitec; 1996.

26. Selli L, Garrafa V. Bioética, solidariedade crítica e voluntariado orgânico. Revista de Saúde Pública 2005; 39(3): 473-478.

27. Boff L. Saber cuidar: ética do humano - compaixão pela terra. Petrópolis, RJ: Vozes; 2003.

28. Matos PES, Tomita NE. A inserção da saúde bucal no Programa saúde da Família: da universidade aos pólos de capacitação. Cadernos de Saúde Pública 2004; 20(6): 1538-1544.

29. Sanchez HF, Drumond MM, Vilaça EL. Adequação de recursos humanos ao PSF: percepçóes de formandos de dois modelos de formação acadêmica em odontologia. Ciência e Saúde Coletiva 2008; 13(2): 523-531.

30. Sánchez CZ, González CV. Ética en el currículo de las carreras de odontología. Acta Bioethica 2008; 14(2): 212-218.

Recebido: 6 de outubro de 2009

Aceito: 15 de dezembro de 2009 